\title{
The Role of Various Powders during the Hydration Process of Cement-Based Materials
}

\author{
Shuhua Liu, Hongling Wang, and Jianpeng Wei \\ State Key Laboratory of Water Resources and Hydropower Engineering Science, Wuhan University, Wuhan 430072, China \\ Correspondence should be addressed to Shuhua Liu; shliu@whu.edu.cn
}

Received 19 June 2017; Accepted 7 August 2017; Published 11 September 2017

Academic Editor: Prinya Chindaprasirt

Copyright (C) 2017 Shuhua Liu et al. This is an open access article distributed under the Creative Commons Attribution License, which permits unrestricted use, distribution, and reproduction in any medium, provided the original work is properly cited.

\begin{abstract}
The role of various powders including glass powder (GP), limestone powder (LP), and steel slag powder (SSP) during the hydration process of cement-based materials was investigated by using X-ray diffraction (XRD), thermogravimetric and differential thermal analysis (TG-DTA), scanning electron microscopy (SEM), and strength tests. GP has adverse impact on early strength, but the pozzolanic reaction at later stage enhances the strength development greatly. LP can significantly improve early strength. SSP has a good contribution to the early and later strength of the paste when its content is less than $15 \%$. GP has little effect on the kind of hydration products but relatively large effects on the quantity. Calcium hydroxide $(\mathrm{CH})$ content of GP paste decreases over curing age gradually, which is different from pure cement paste because its pozzolanic activity consumes more $\mathrm{CH}$ than that generated from the cement hydration. SSP and LP mainly play a role of filling effect at early stage. Nucleating effect of LP also promotes the early hydration of cement. The hydration of LP occurs at later stage and forms the calcium carboaluminate hydrates. The hydration of SSP is relatively slow, which generates $\mathrm{CH}$ at later stage and is effective in the strength development.
\end{abstract}

\section{Introduction}

Mineral admixture has become an indispensable component in concrete because it generally has some pozzolanic reactivity during the hydration process. Mineral admixture can replace cement and reduce cost of concrete; moreover, it can improve the workability of fresh concrete or some properties of hardened concrete. Therefore, the use of mineral admixture in concrete brings significant benefits.

Glass powder (GP) is ground waste glass which mainly comes from industrial waste glass (such as flat glass and glass fiber) and household waste glass (such as glass containers and light bulbs) [1]. GP has not been used as a cement replacement until recent years. It is amorphous and contains large quantities of silicon and calcium. Soda-lime glass is pozzolanic or even cementitious in theory when it is ground enough [1]. The use of GP in cementitious materials can effectively enhance the strength and inhibit the ASR reaction of the system [2-4]. GP was used to prepare reactive powder concrete (RPC) by replacing partial Portland cement to reduce the cost $[5,6]$. It is found that using Portland cement, glass powder, silica fume, and water reducer can prepare high performance concrete with compressive strength up to $100 \mathrm{MPa}$. Concrete with GP has improved properties, that is, higher strength, lower dry shrinkage, and so on than those of the concrete with fly ash $[3,7]$. However, the study on the action mechanism of GP in cement-based materials is still at the initial stage.

The main component of limestone powder (LP) is calcite $\left(\mathrm{CaCO}_{3}\right)$, which is a cheap and easily available material. At present, LP is mainly used to replace partial fine aggregate or as mineral admixture in the concrete. As a mineral admixture, LP is observed to have hydration reactivity when it is ground to a certain degree of fineness and it needs to have a certain environment and enough hydration time [8]. LP reacts with aluminum phase in cement clinker to form calcium carboaluminate hydrates, which effectively accelerates the hydration and hardening process [9], and thus improves the properties of concrete $[10,11]$.

Steel slag powder (SSP) is the slag exhausted from converter, electric furnace, and refining furnace, whose main components are silicate and ferrite. In developed countries, the majority of SSP is used as aggregate in concrete [12]. China has studied the application of SSP as mineral admixture in 
TABLE 1: Chemical compositions of raw materials/mass, $\%$.

\begin{tabular}{lcccccccccc}
\hline Compositions & $\mathrm{SiO}_{2}$ & $\mathrm{Al}_{2} \mathrm{O}_{3}$ & $\mathrm{CaO}$ & $\mathrm{Fe}_{2} \mathrm{O}_{3}$ & $\mathrm{MgO}$ & $\mathrm{SO}_{3}$ & $\mathrm{~K}_{2} \mathrm{O}$ & $\mathrm{Na}_{2} \mathrm{O}$ & $\mathrm{P}_{2} \mathrm{O}_{5}$ & loss \\
\hline Cement & 21.25 & 2.91 & 63.09 & 3.24 & 0.68 & 3.36 & 1.12 & 0.31 & 0.17 & 3.52 \\
$\mathrm{GP}$ & 55.75 & 10.64 & 6.60 & 0.28 & 1.01 & 0.27 & 0.54 & 9.92 & 0.03 & 11.9 \\
LP & 1.79 & 0.56 & 54.69 & 0.35 & 0.40 & 0.03 & - & 0.06 & - & 41.93 \\
SSP & 14.11 & 3.51 & 42.39 & 17.45 & 6.60 & 0.50 & 0.13 & 0.22 & 1.63 & 8.72 \\
\hline
\end{tabular}

recent thirty years. The studies have shown that SSP can be used as a kind of active cementitious material, but its activity is much lower than that of cement clinker.

Recently, little existing literatures focused on investigation of the hydration properties and process of the three various powders. As mineral admixtures, the hydration process and strength development of cement-based materials containing the three powders are relatively different. In this paper, GP, LP, and SSP will be used as mineral admixtures to study the role during the hydration process of cement-based materials.

\section{Experimental}

The ordinary Portland cement PO 42.5 (POC) complied with the Chinese standard GB175-2007 is used in this test. The chemical compositions of GP, LP, SSP, and POC determined by $\mathrm{X}$-ray fluorescence (XRF) are listed in Table 1 . The main compositions of $\mathrm{GP}$ are $\mathrm{SiO}_{2}, \mathrm{Al}_{2} \mathrm{O}_{3}$, and $\mathrm{Na}_{2} \mathrm{O}$ accounting for $55.75 \%, 10.64 \%$, and $9.92 \%$, respectively. LP contains high content of $\mathrm{CaCO}_{3}$, which mainly relied on raw limestone. The content of $\mathrm{CaO}, \mathrm{Fe}_{2} \mathrm{O}_{3}$, and $\mathrm{SiO}_{2}$ in SSP is around $74 \%$, because the source of steel slag is iron and steel materials, smelting slag material, eroded lining refractory, and the sediment carried by the solid material. SSP contains $\mathrm{C}_{2} \mathrm{~S}$, which can also be detected by XRD test.

$40 \mathrm{~mm} \times 40 \mathrm{~mm} \times 40 \mathrm{~mm}$ paste specimens used in this paper were prepared by the paste mixer with water to binder ratio of 0.4 . All the specimens were cured in normal environment with relative humidity $(\mathrm{RH})$ higher than $90 \%$ and temperature of $20 \pm 2^{\circ} \mathrm{C}$ till the stipulated age of 3,7 , 28, and 90 days. The mixture ratios are shown in Table 2. The content of mineral mixtures in cementitious system is $15 \%, 30 \%$, and $45 \%$ by mass. The samples containing $30 \%$ powders were used for microtest. The compressive strength of the pastes at different ages was tested by WAY-2000, a battery solution type compression testing machine. Specific test procedure is referred to GB/T17671-1999, Method of Testing Cement-Determination of Strength. The cores of broken pastes were collected to be soaked in anhydrous ethanol to stop the continued hydration for SEM tests. Before XRD and TG-DTA tests, the specimens were removed from the ethanol and quickly ground into powder in the agate mortar and dried in $60^{\circ} \mathrm{C}$ for 2 hours to avoid carbonization. The chemical compositions were measured by Axios advanced $\mathrm{X}$-ray fluorescence instrument, in voltage range from 30 to $60 \mathrm{kV}$, current 50 to $100 \mathrm{~mA}$. Morphology of the specimens was investigated by using a SEM (JSM-5610LV, Japan). The XRD was detected by X'Pert Pro, PANalytical of Netherland, with scanning speed of $6^{\circ} / \mathrm{min}$. The TG-DTA experiments
TABLE 2: Mix proportions of the cement pastes/g.

\begin{tabular}{lccccc}
\hline Samples & Cement & GP & LP & SSP & Water \\
\hline PC & 600 & 0 & 0 & 0 & 240 \\
\hline GP-15 & 510 & 90 & 0 & 0 & 240 \\
GP-30 & 420 & 180 & 0 & 0 & 240 \\
GP-45 & 330 & 270 & 0 & 0 & 240 \\
\hline LP-15 & 510 & 0 & 90 & 0 & 240 \\
LP-30 & 420 & 0 & 180 & 0 & 240 \\
LP-45 & 330 & 0 & 270 & 0 & 240 \\
\hline SSP-15 & 510 & 0 & 0 & 90 & 240 \\
SSP-30 & 420 & 0 & 0 & 180 & 240 \\
SSP-45 & 330 & 0 & 0 & 270 & 240 \\
\hline
\end{tabular}

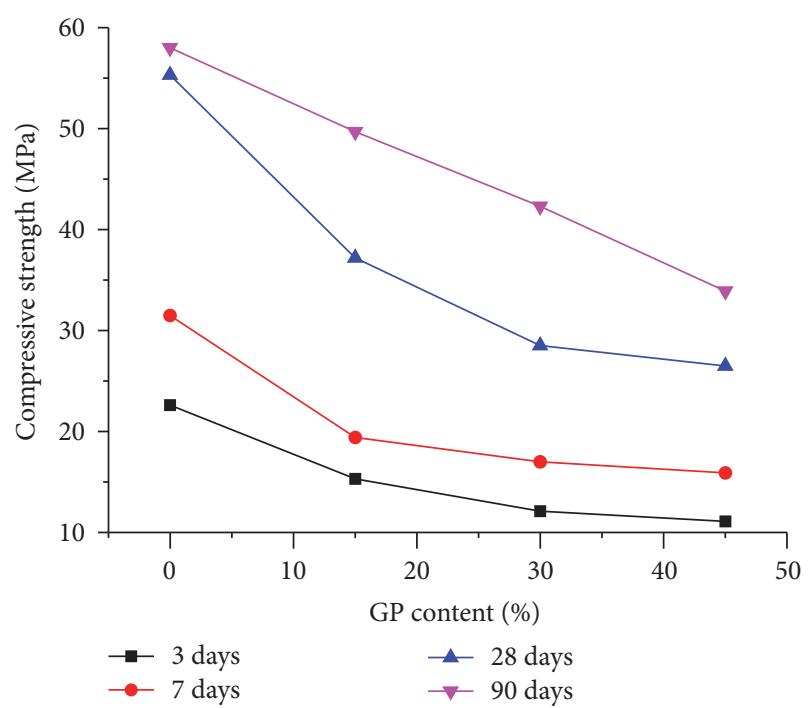

FIGURE 1: Effect of GP content on the compressive strength of the paste.

were measured on the Diamond TG/DTA analyzer, produced by Perkin Elmer Instruments Plant (Shanghai), in the temperature range from 0 to $900^{\circ} \mathrm{C}$, using platinum crucibles with approximately $4 \mathrm{mg}$ of sample, under dynamic $\mathrm{N}_{2}$ atmosphere $(50 \mathrm{~mL} / \mathrm{min})$.

\section{Results and Discussion}

3.1. Strength. Figures 1-3 present the compressive strength of the three groups. According to the results, GP reduces the early strength of the paste, and the strength reduction becomes more obvious with the increase of GP content, which indicates that GP has significant adverse effect on the 


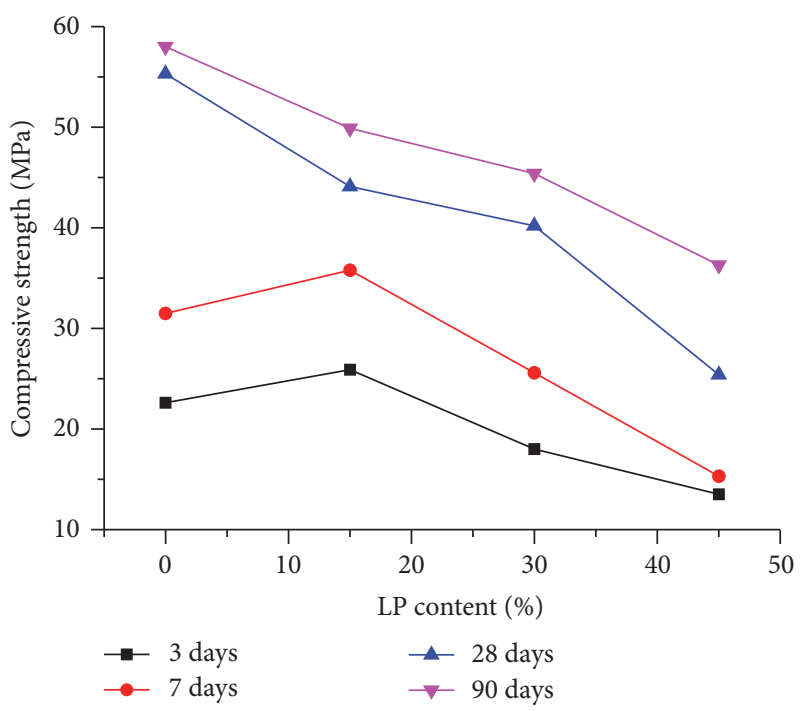

FIGURE 2: Effect of LP content on the compressive strength of the paste.

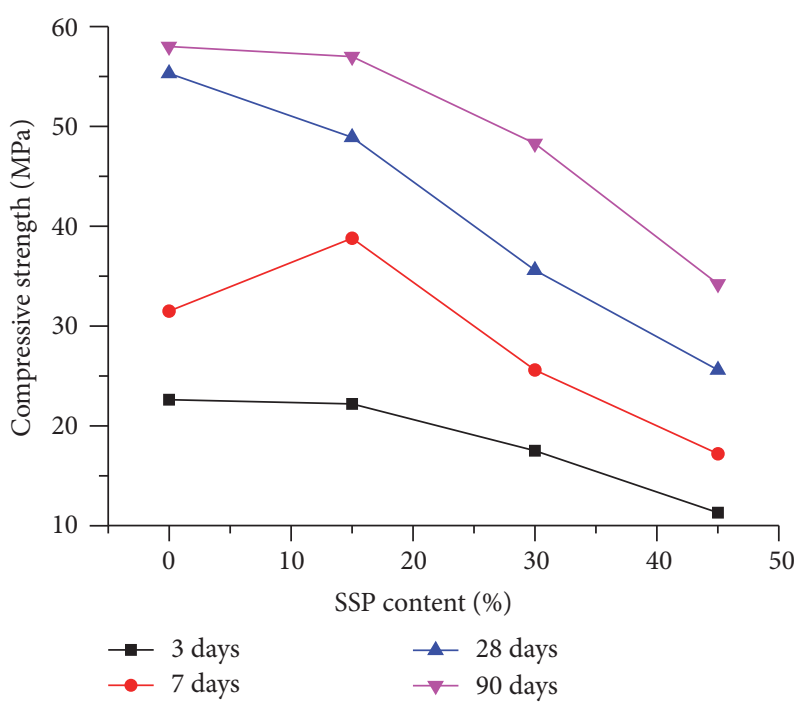

FIGURE 3: Effect of SSP content on the compressive strength of the paste.

strength of the composite cementitious materials. But, the later strength of the GP sample improves faster than that of the pure cement (PC) sample. The strength of PC paste at 90 days increases $4.9 \%$ higher than that at 28 days, while GP-15, GP-30, and GP-45, respectively, increase 33.7\%, 48.3\%, and $17.9 \%$. The characteristics of the multiedges and smooth surface of the glass particles might reduce the early mechanical properties of the cementitious system. Furthermore, GP has no independent hydraulicity but has high pozzolanic activity. At the later stage, GP reacts with $\mathrm{Ca}(\mathrm{OH})_{2}$, the hydration product of cement, and generates calcium silicate hydrate (C$\mathrm{S}-\mathrm{H})$ which makes the microstructure denser and improves strength.

Different from GP group, the strength of LP group at 3 and 7 days first increases and then decreases along with the increase of LP content. When the content is $15 \%$, the paste strength increases obviously.

When the content increases to $30 \%$, the paste strength decreases and is lower than that of PC sample. The strength at 28 and 90 days is all less than that of PC sample. Moreover, the more the LP content is, the more the strength decreases. The reason is that a proper content of LP provides the nucleation site [13] for cement hydration at early stage, which promotes early hydration of cement [14] and thus improves the strength; but at the later stage, the hydrates from the cementitious system containing LP are less than that of PC sample, resulting in lower strength [15].

The strength of SSP group increases along with the curing age. 15\% SSP content has little reduction effect on the strength and the strength at 7 days even is higher than that of PC sample. When the content is $30 \%$ or higher than $30 \%$, the strength decreases rapidly, which suggests that large amount of SSP is disadvantageous to the strength.

In order to analyze the activity of the three powders, the activity index [16] is used to reflect their activity. The calculation progress is as formulas (1) to (3). Here, $R_{s a}$ is the relative strength of cement paste containing powders, $R_{a}$ is the strength of cement paste containing powders, and $q_{0}$ is the mass fraction of the cement. For the reference (PC sample), $q_{0}=100$, its relative strength is $R_{s c} . R_{c}$ is the reference strength,

$$
\begin{aligned}
R_{s a} & =\frac{R_{a}}{q_{0}}, \\
R_{s c} & =\frac{R_{c}}{100} .
\end{aligned}
$$

Although the cement content of the paste containing various powders decreases correspondingly compared to PC group, $R_{a}$ is higher than $R_{c}$ and $R_{s a}$ is higher than $R_{s c}$ in general because of the enhancement of hydration activity effect. And the difference between the two is relative strength of the hydration activity effect contribution, which is called relative strength of hydration activity $\left(R_{s p}\right)$. The calculation is formula

$$
R_{s p}=R_{s a}-R_{s c} .
$$

Thus a relative index is obtained, which is the contribution rate of hydration activity $\left(P_{a}\right)$, which can be used to characterize the hydration activity contribution of the powders in the cement paste. The calculation formula is as follows, and the results are shown in Table 3:

$$
P_{a}=\frac{R_{s p}}{R_{s a}}=\frac{R_{s a}-R_{s c}}{R_{s a}}=1-\frac{R_{s c}}{R_{s a}}=1-\frac{R_{c} * q_{0}}{R_{a} * 100} .
$$

The contribution rate of GP increases along with the curing time. The value of contribution rate developing from early negative to the late positive reveals that the pozzolanic reaction degree of GP at the later stage is significantly higher than that at the early stage. LP's early contribution rate is high and decreases along with the curing time in general, which indicates that the early filling effect and accelerating effect obviously improve the strength of the paste, but the later hydration 
TABLE 3: The compressive strength contribution rate of the mineral mixtures' hydration activity.

\begin{tabular}{lcccc}
\hline Samples & 3 days & 7 days & 28 days & 90 days \\
\hline GP-15 & -0.25 & -0.38 & -0.26 & -0.10 \\
GP-30 & -0.31 & -0.30 & -0.36 & 0.04 \\
GP-45 & -0.12 & -0.09 & -0.15 & 0.06 \\
\hline LP-15 & 0.26 & 0.25 & -0.06 & 0.01 \\
LP-30 & 0.13 & 0.14 & 0.04 & 0.11 \\
LP-45 & 0.08 & -0.13 & -0.20 & 0.12 \\
\hline SSP-15 & 0.14 & 0.25 & 0.04 & 0.14 \\
SSP-30 & 0.10 & 0.14 & -0.08 & 0.16 \\
SSP-45 & -0.10 & -0.01 & -0.19 & 0.07 \\
\hline
\end{tabular}
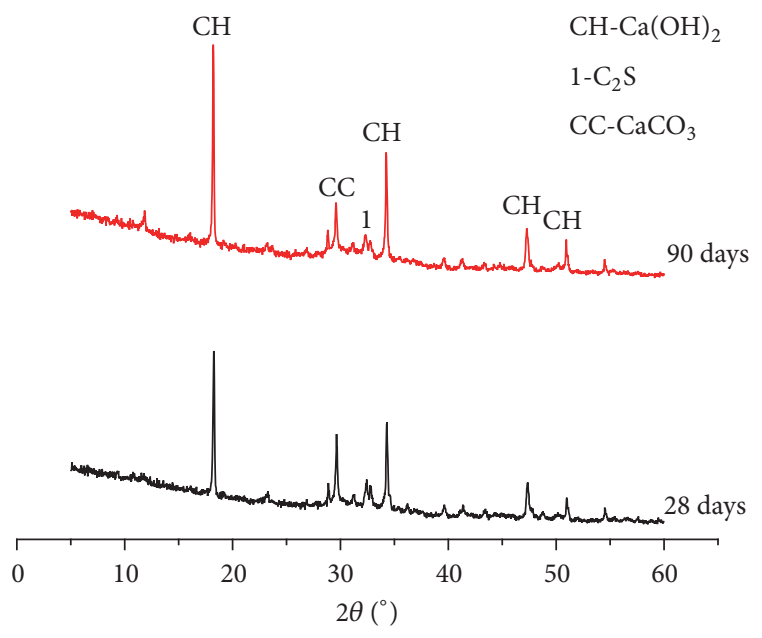

FIGURE 4: XRD patterns of PC paste at different curing ages.

activity is low. SSP has better early filling effect and the later hydration activity works a long time; thus the SSP group has higher early and later contribution rate than GP group.

\subsection{Hydration Products}

3.2.1. XRD. Figures 4-7 display the hydration products of the pastes with different powders. The main crystal hydrates of GP samples are similar to those of $\mathrm{PC}$ paste, that is, $\mathrm{Ca}(\mathrm{OH})_{2}$ $(\mathrm{CH})$, calcium aluminate hydrate $(\mathrm{CAH})$, and unreacted clinker, because the main chemical compositions of GP and cement are similar. Compared with the PC sample, the $\mathrm{CH}$ of GP group decreases gradually along with curing time, because GP consumes some $\mathrm{CH}$ by pozzolanic reactivity at the later stage. GP has feeble pozzolanic reactivity at early stage, which mainly occurs at later stage. The pozzolanic reactivity of GP needs to be under certain excitation conditions, such as enough alkali, thermal, and physical conditions [17]. In this experiment, the pozzolanic reactivity of GP is excited by an alkaline environment produced by cement hydration.

Compared with GP group, Figure 6 displays that $\mathrm{CH}$ diffraction peak of LP group significantly reduces, while $\mathrm{CaCO}_{3}$ (CC) diffraction peak is greatly enhanced, which is main composition of LP. A small amount of calcium carboaluminate hydrates $\mathrm{C}_{3} \mathrm{~A}-\mathrm{CaCO}_{3}-11 \mathrm{H}_{2} \mathrm{O}$ diffraction peak can
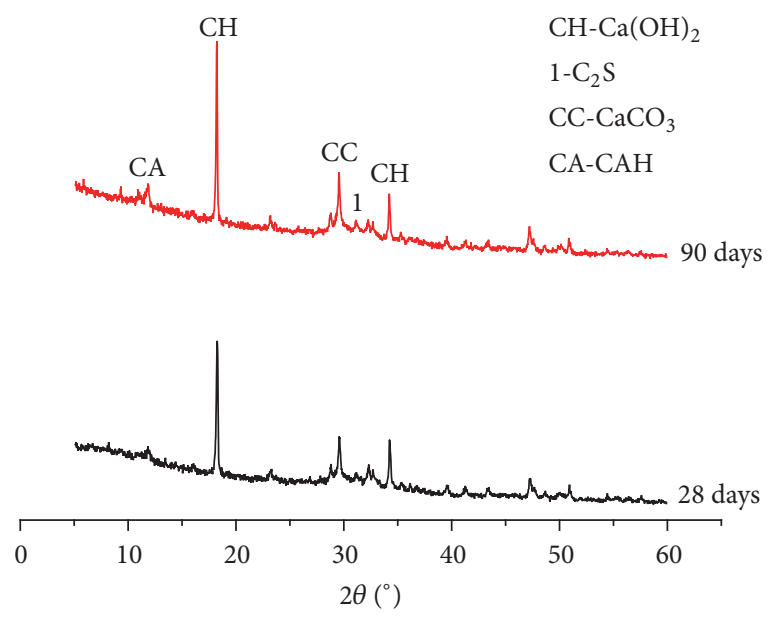

FIGURE 5: XRD patterns of GP-30 cement paste at different curing ages.
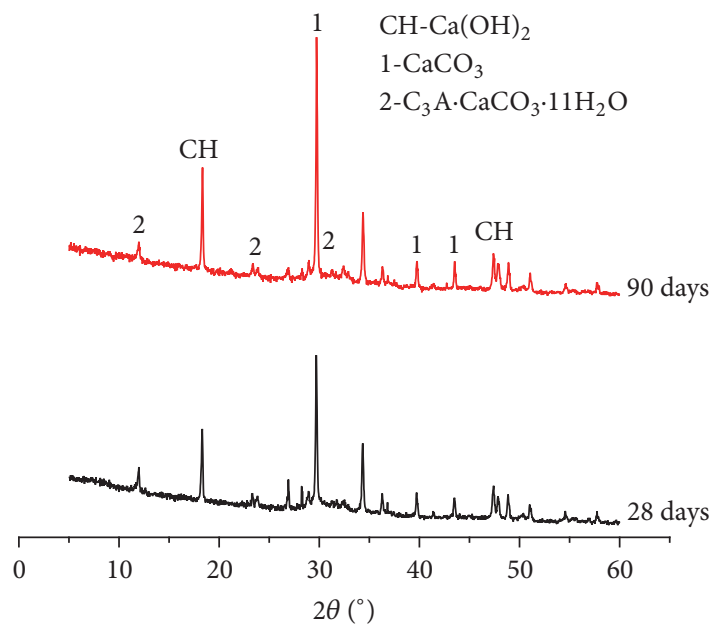

FIGURE 6: XRD patterns of LP-30 cement paste at different curing ages.

be found at 90 days but hardly found at 28 days. It is probably because the cement contains a little $\mathrm{C}_{3} \mathrm{~A}$ and $\mathrm{LP}$ reacts with $\mathrm{C}_{3} \mathrm{~A}$ in cement to generate carboaluminate hydrates; thus it has a little strength contribution rate at later stage. The formation of calcium carboaluminate hydrates has been found in other researches, the generation time may be at 7 to 127 days, and the time is based on reaction activity of different LP [18].

Figure 7 displays XRD pattern of SSP, which shows that SSP contains $\mathrm{C}_{2} \mathrm{~S}$. Figure 8 displays the hydration products of SSP group at 28 days and 90 days. The main crystal hydration products are $\mathrm{CH}$, the unhydrated clinker, and a small amount of CC. The $\mathrm{CH}$ content of SSP group gradually increases along with the curing time because SSP consumes no $\mathrm{CH}$ but $\mathrm{C}_{2} \mathrm{~S}$ generates $\mathrm{CH}$, and the cement hydration continues to produce $\mathrm{CH}$, so the $\mathrm{CH}$ content will increase overall which proves that the later strength contribution rate of SSP can keep high over a long time.

3.2.2. TG-DTA. The TG-DTA curves of the pastes are shown in Figures 9-12. The characteristics of all TG-DTA curves 


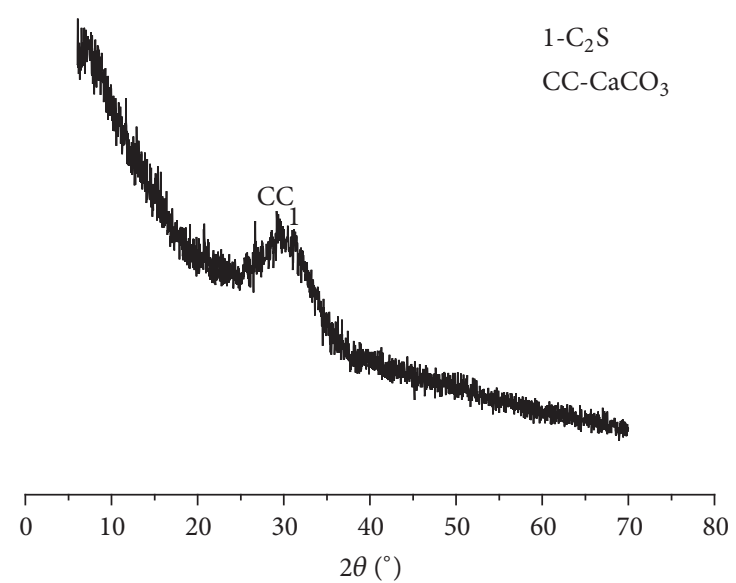

FIGURE 7: XRD pattern of SSP.

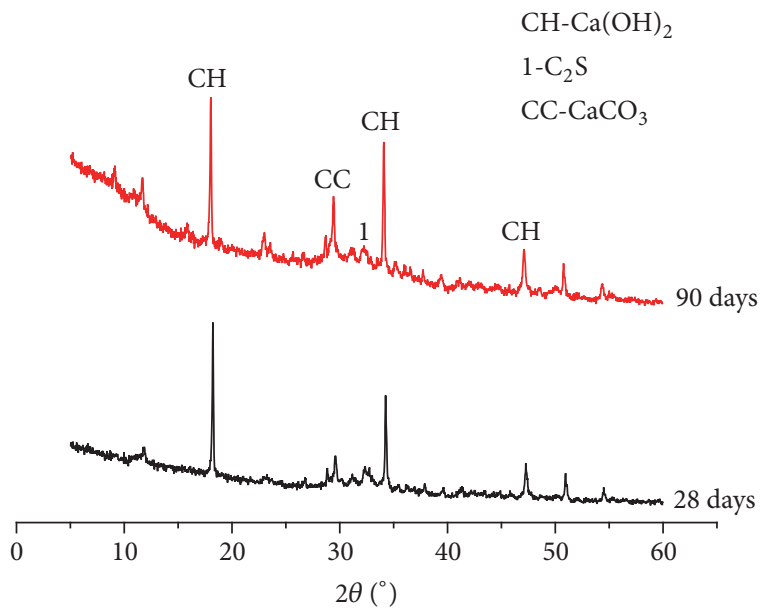

FIGURE 8: XRD patterns of SSP-30 cement paste at different curing ages.

are roughly the same. All the DTA curves have an obvious endothermic peak at 400 to $500^{\circ} \mathrm{C}$ where the samples mainly take off the coordinated water. The position of highest endothermic peak is about $470^{\circ} \mathrm{C}$ which is caused by the $\mathrm{CH}$ and C-S-H's (mainly $\mathrm{CH}$ ) dehydrated decomposition where the TG curves have a significant weight loss gradient which relates to the weight loss of $\mathrm{CH}$ [19].

Based on the endothermic peak and the weight loss rate of TG-DTA curves, the $\mathrm{CH}$ content can be calculated quantitatively. The dehydrated decomposition of $\mathrm{CH}$ will occur at 400 to $500^{\circ} \mathrm{C}$ which will result in a loss in quality and the content of $\mathrm{CH}$ can be calculated as formula (4). The $\mathrm{CH}$ content is shown in Figure 13.

$$
\begin{array}{cc}
\mathrm{Ca}(\mathrm{OH})_{2} & \longrightarrow \mathrm{CaO}+\mathrm{H}_{2} \mathrm{O} \\
74 & 18 \\
W_{\mathrm{CH}} & W_{\mathrm{H}}
\end{array}
$$

Figure 13 indicates that the $\mathrm{CH}$ content of LP sample, in accordance with PC sample, increases gradually over curing time which is consistent with the $\mathrm{CH}$ diffraction peaks of

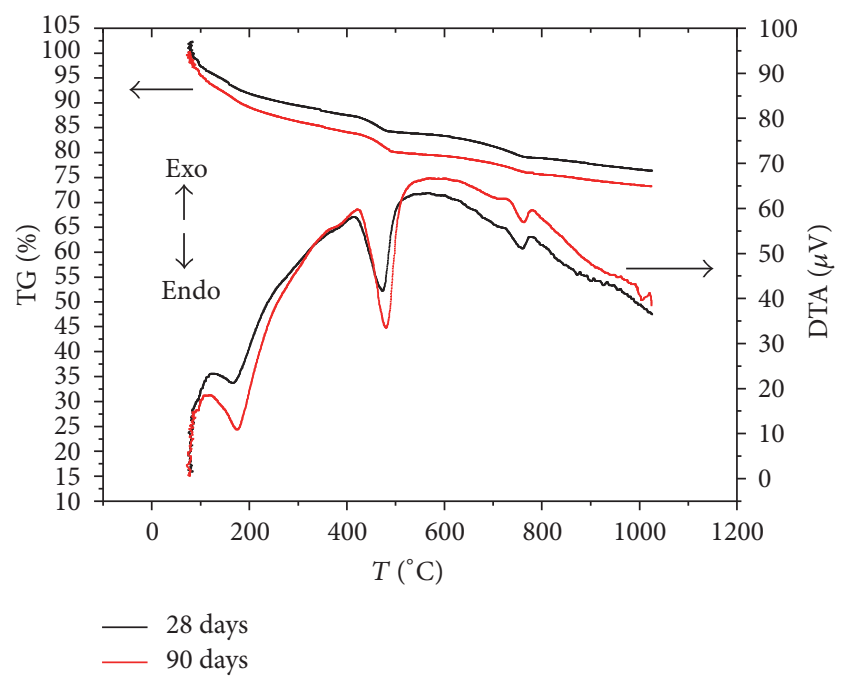

Figure 9: TG-DTA curves of PC paste at different curing ages.

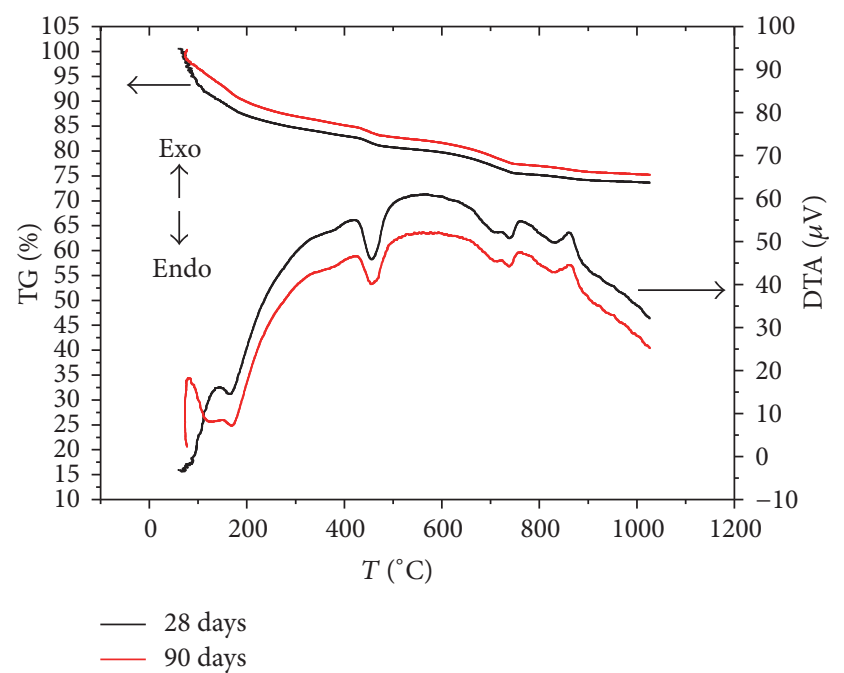

Figure 10: TG-DTA curves of GP-30 cement paste at different curing ages.

XRD patterns. And it is the same as SSP sample because both cement and SSP can generate $\mathrm{CH}$ instead of the $\mathrm{CH}$ consumption resulting from the pozzolanic hydration which has been proven by the XRD patterns. Different from PC, LP, and SSP, the CH content of GP sample declines along with the curing time because GP consumes $\mathrm{CH}$ during the pozzolanic reaction, which has also been revealed in the XRD patterns. Along with the curing time, on the one hand, the cement generates $\mathrm{CH}$; on the other hand, GP consumes some $\mathrm{CH}$. In fact, the amount of $\mathrm{CH}$ changing along with curing time is determined by the relative content of cement and GP and their reaction speed.

3.2.3. SEM. SEM images of the pastes at 28 and 90 days are shown in Figures 14-17. Figure 14(a) reveals that PC paste at 28 days has a large amount of fibrous C-S-H gel, some needleshaped ettringite, and hexagonal $\mathrm{CH}$ crystals which forms a framework by staggering, overlapping to a network structure 


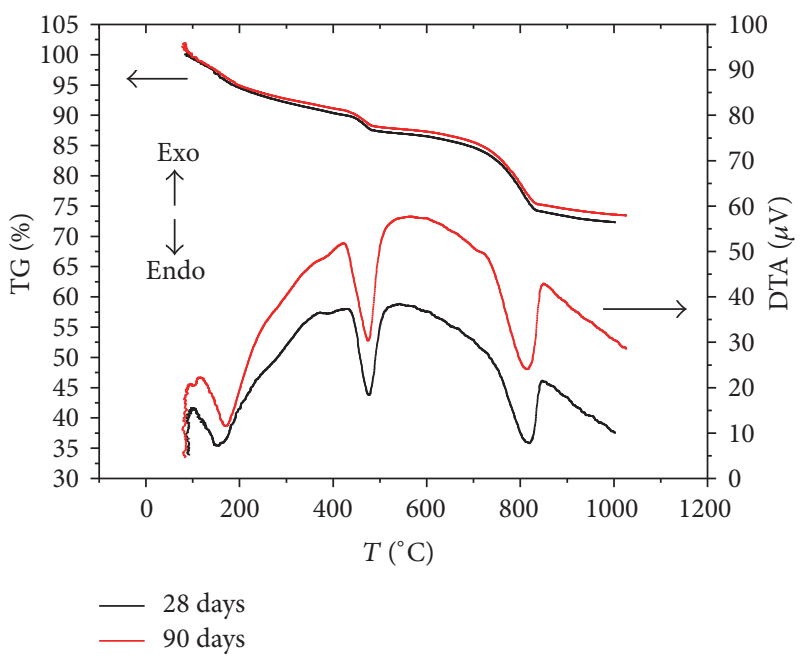

FIGURE 11: TG-DTA curves of LP-30 cement paste at different curing ages.

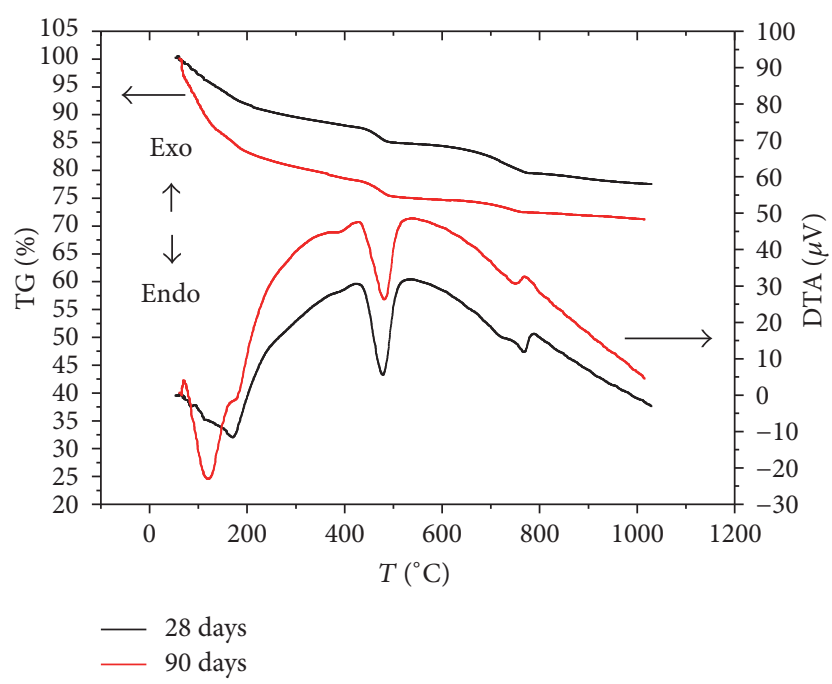

FIgURE 12: TG-DTA curves of SSP-30 cement paste at different curing ages.

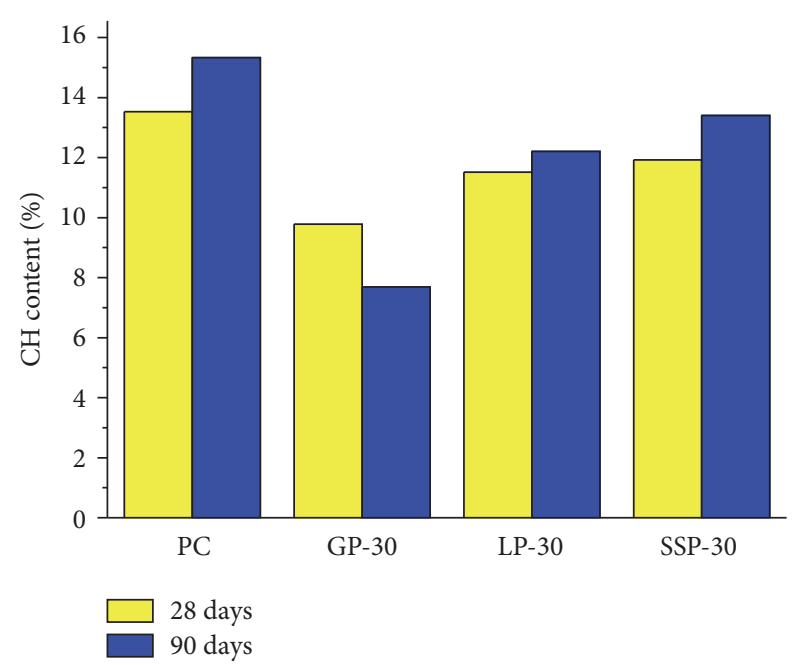

FIGURE 13: $\mathrm{CH}$ content of the pastes at different curing ages. and connecting with the surrounding unhydrated cement particles. But, the microstructure of the paste at 28 days appears loose. Figure 14(b) displays that the cement hydration is more adequate over curing age, and various hydration products fill into the original loose pores and form dense microstructure. The more hydration products are produced over curing age, similar to the TG-DTA and XRD results.

Similar to the PC sample, a large number of fibrous C-S-H gel can also be observed in Figure 15(a), and sometimes it also presented strip or rod-like, tubular, foil-like sheet [20]. The microstructure of the paste containing GP becomes denser than that of PC sample; it is difficult to observe and identify the crystal phases. GP plays the role as the filler at the early stage. It can be found from Figure 15(b) that the paste has formed dense microstructure, and most of the hydration products are unable to identify from the morphology. GP consumes $\mathrm{CH}$ generated by cement hydration and forms $\mathrm{C}$ S-H gel, which has been proven by XRD and TG-DTA tests. C-S-H gel connects with other hydrates and forms a denser entirety, which plays an important role in the improvement of strength and microstructure and illustrates why the strength contribution rate of GP becomes positive at the later stage.

Figure 16(a) displays that the hydration products of LP-cement paste at 28 days adhere to the surface of LP particles. The hydration products of $\mathrm{C}_{3} \mathrm{~S}$ generate free $\mathrm{Ca}^{2+}$ which will produce hydration products along the surface of limestone particles; this is the so-called "crystal nucleus effect." This effect can promote the early cement hydration and increase the early strength but hinder the development of later strength, which is consistent with the strength test. Figure 16(b) shows that the C-S-H gel presents II type network at 90 days. At the same time, LP particle surface has been eroded, which confirms that LP takes part in the later hydration reaction again.

Figure 17(a) shows that the microstructure is loose; thus the early hydration degree of SSP is very low at 28 days. It can be seen from Figure 17(b) that C-S-H gel has been basically filled in the pore system at 90 days. The surface of the SSP has been corroded seriously and covered by C$\mathrm{S}-\mathrm{H}$ gel which indicates that SSP reacts with cement at the later stage. $\mathrm{CH}$ crystals have been gradually surrounded by other hydration products and formed dense microstructure, which better explains why SSP has a relative high strength contribution rate over a long time.

\section{Conclusions}

(1) GP has negative effect on the early strength but a high strength development due to the pozzolanic reaction at later stage. LP can obviously improve the early strength, especially at 3 and 7 days; it mainly plays a role of filling effect and nucleating effect at the early stage and reactive effect at later stage. SSP has a high contribution to the early and later strength of the paste when its content is under $15 \%$. The early filling effect and the later hydration of SSP improve the strength contribution rate over a long time.

(2) GP has little effect on the kind of hydration products, but relatively large effect on the quantity. $\mathrm{CH}$ content of PC sample increases gradually along with the curing age, 


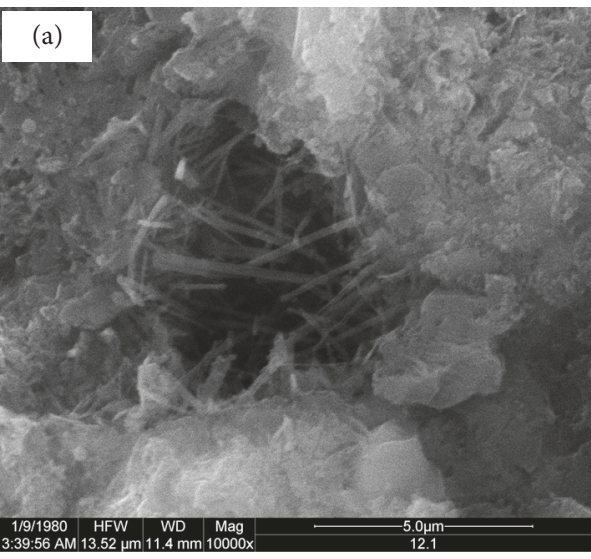

(a)

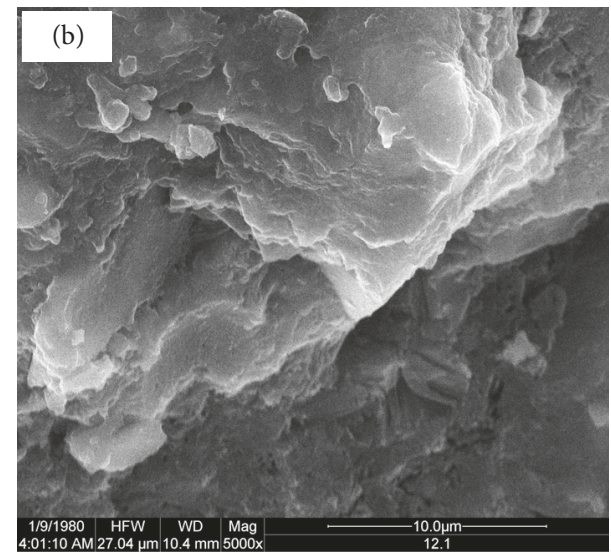

(b)

FIGURE 14: SEM images of PC samples at curing age of (a) 28 days and (b) 90 days.

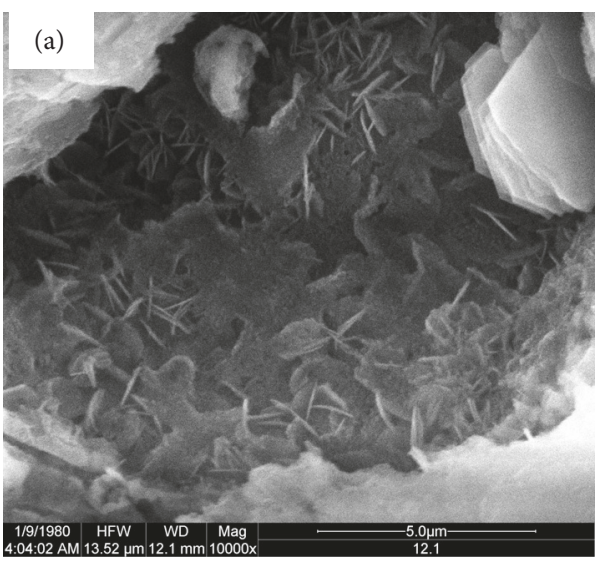

(a)

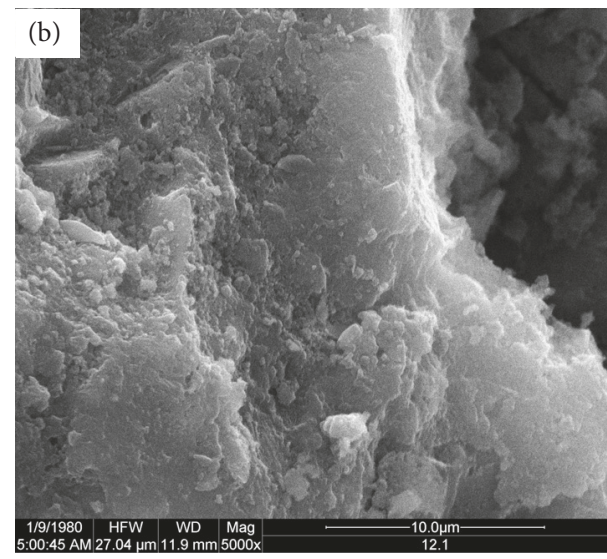

(b)

FIGURE 15: SEM images of GP-30 cement samples at curing age of (a) 28 days and (b) 90 days.

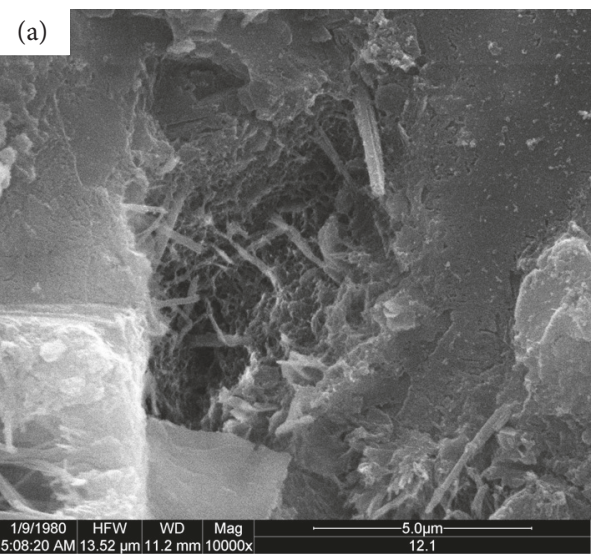

(a)

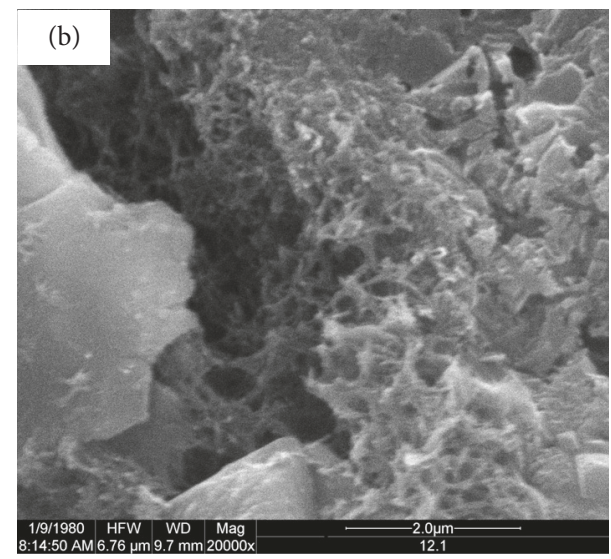

(b)

FIGURE 16: SEM images of LP-30 cement samples at curing age of (a) 28 days and (b) 90 days. 


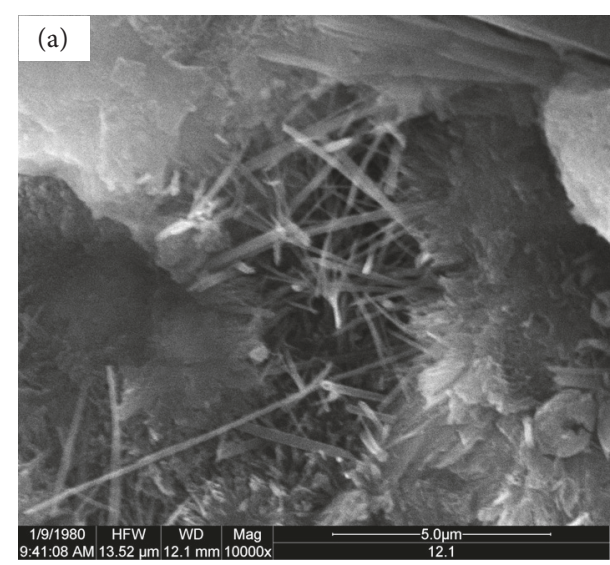

(a)

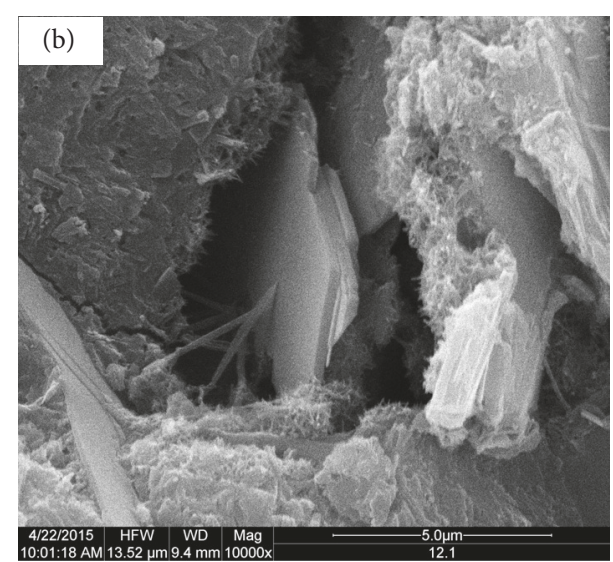

(b)

FIGURE 17: SEM images of SSP-30 cement samples at curing age of (a) 28 days and (b) 90 days.

while the GP group is contrary. The $\mathrm{CH}$ content produced by cement hydration gradually increases, which stimulates the pozzolanic activity of GP; GP consumes $\mathrm{CH}$ more than that cement hydration generates. And $\mathrm{CH}$ content of LP and SSP samples are similar to PC group which increases along with curing age. The LP hydration product calcium carboaluminate hydrates can be detected by XRD and also be confirmed by SEM. The active substances $\mathrm{C}_{2} \mathrm{~S}$ of SSP generate $\mathrm{CH}$ at the later stage.

(3) GP, LP, and SSP mainly play the role of filling effects at the early stage, and the nucleating effect of LP promotes the early hydration of cement. The surface of GP, LP, and SSP has been eroded at 90 days indicating that they take part in hydration reaction at later stage, which is also proven by the strength tests.

\section{Conflicts of Interest}

The authors declare that they have no conflicts of interest.

\section{Acknowledgments}

This project is funded by the National Key R\&D Program of China (2016YFC0401907) and Opening Funds of Guangxi Key Laboratory of New Energy and Building Energy Saving (15-J-22-4-001).

\section{References}

[1] Z. Z. Bian, "The recycle and utilization of waste glass in China looked from the practice of developed countries," Glass, vol. 60, no. 1, pp. 51-55, 2003.

[2] G. S. Xie, Y. N. Kong, and S. H. Liu, "Research progress on alkali aggregate reaction of glass concrete," Advanced Materials Industry, no. 7, pp. 65-71, 2012.

[3] A. Shayan and A. Xu, "Value-added utilisation of waste glass in concrete," Cement and Concrete Research, vol. 34, no. 1, pp. 8189, 2004.

[4] W. Jin, Alkali-silica reaction in concrete with glass aggregate: a chemo-physico-mechanical approach [Ph.D. thesis], Columbia University, New York, NY, USA, 1998.
[5] S. H. Liu, Z. H. Xu, Y. B. Sun et al., "Study on the application of waste glass powder in ultra-high performance cement-based material," China Concrete and Cement Products, no. 11, pp. 7779, 2012.

[6] C. Qu, Z. Y. Gao, S. H. Liu et al., "Study on the application of waste glass powder in reactive powder concrete," Concrete, no. 8, pp. 82-84, 2011.

[7] N. Schwarz and N. Neithalath, "Influence of a fine glass powder on cement hydration: comparison to fly ash and modeling the degree of hydration," Cement and Concrete Research, vol. 38, no. 4, pp. 429-436, 2008.

[8] L. D. Zhang and J. M. Mou, Nanostructures and Nanomaterials: Synthesis, Properties, and Applications, The Science Publishing Company, 2001.

[9] G. Kakali, S. Tsivilis, E. Aggeli, and M. Bati, "Hydration products of $\mathrm{C}_{3} \mathrm{~A}, \mathrm{C}_{3} \mathrm{~S}$ and Portland cement in the presence of $\mathrm{CaCO}_{3}$," Cement and Concrete Research, vol. 30, no. 7, pp. 10731077, 2000.

[10] P. Poitevin, "Limestone aggregate concrete, usefulness and durability," Cement and Concrete Composites, vol. 21, no. 2, pp. 89-97, 1999.

[11] P. Lu and S. B. Lu, "Effect of $\mathrm{CaCO}_{3}$ on hydration of $\mathrm{C}_{3}$ S," Journal of the Chinese Ceramic Society, vol. 15, no. 4, pp. 28-32, 1987.

[12] J. N. Murphy and T. R. Meadow, "Enhancement of the cementitious properties of steelmaking slag," Canadian Metalurgical Quarterly, vol. 36, no. 5, pp. 331-335, 1997.

[13] S. H. Liu, "Influence of limestone powder on the hydration characteristic of complex binder," Journal of Building Materials, vol. 13, no. 2, pp. 218-221, 2010.

[14] R. J. Detwiler and P. D. Tennis, The Use of Limestone in Portland Cement: A State of the Art Review, Portland Cement Asociation, Skokie, Ill, USA, 1996.

[15] H. Yuan, "The influence of limestone powder on concrete performance," Central South University, vol. 21, no. 2, pp. 13-15, 2009.

[16] X. C. Pu, Ultra-High Strength High Performance Concrete, Chongqing University Press, 2004.

[17] Q. B. Yang, S. Zhang, S. Huang, and Y. He, "Effect of ground quartz sand on properties of high-strength concrete in the steam-autoclaved curing," Cement and Concrete Research, vol. 30, no. 12, pp. 1993-1998, 2000. 
[18] W. A. Klemm and L. D. Adama, Carbonate Additions to Cement, American Society for Testing and Materials, Philadelphia, Pa, USA, 1990.

[19] Z. F. Xu, M. X. Zhang, and J. H. Li, "Study on properties of low grade compressive strength cement-based composite materials modified by superfine silica fume," Bulletin of the Chinese Ceramic Society, vol. 31, no. 2, pp. 401-405, 2012.

[20] R. Z. Yuan, Cementitious Materials Science, Wuhan University of Technology Press, 1996. 

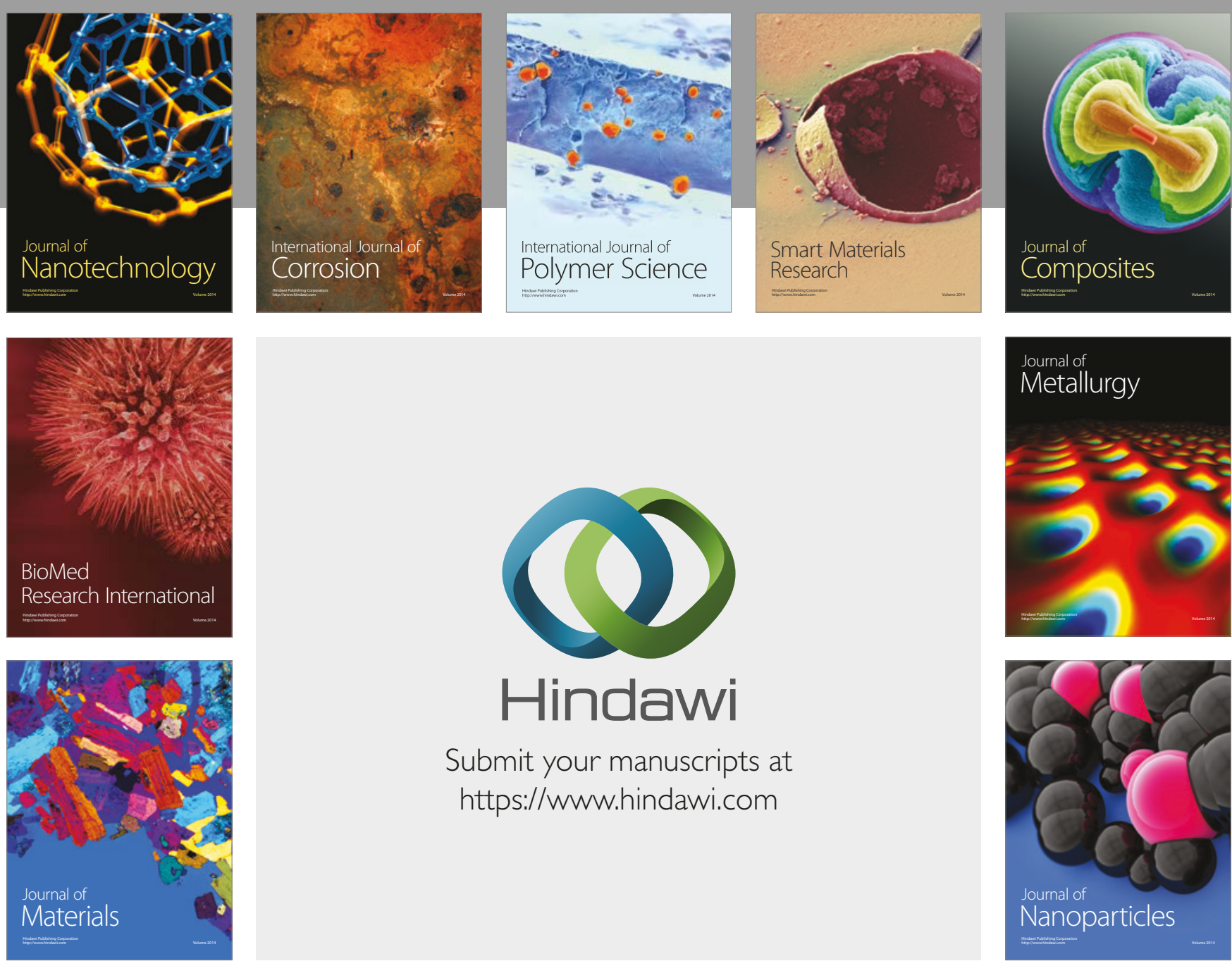

\section{Hindawi}

Submit your manuscripts at

https://www.hindawi.com
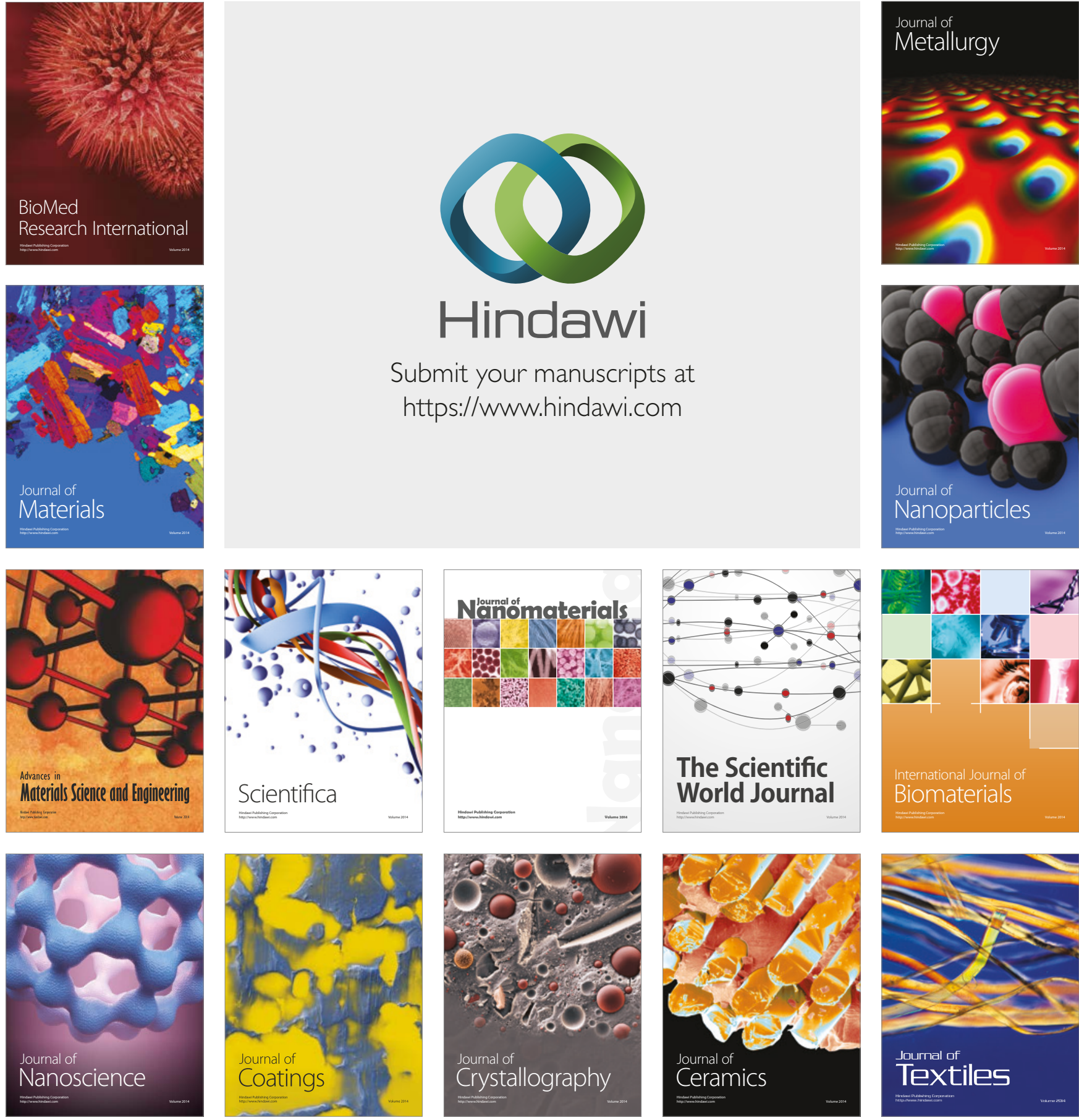

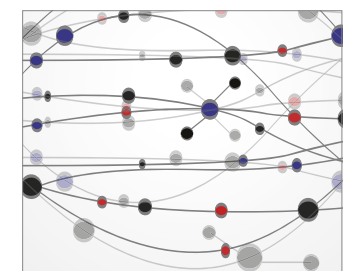

The Scientific World Journal
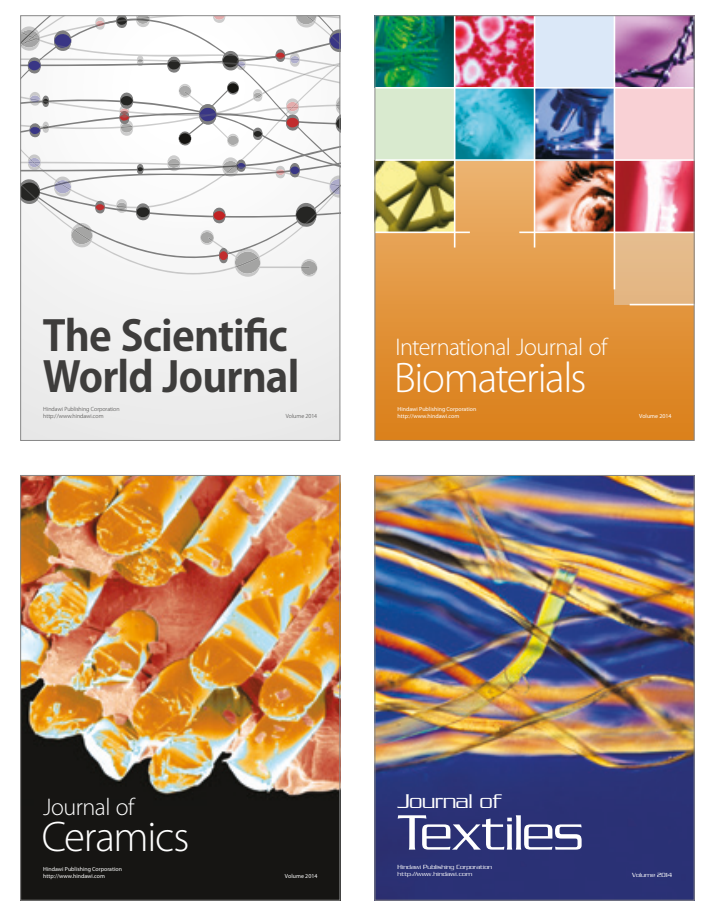